\title{
Machado de Assis, um Poeta Satírico?
}

\author{
Anselmo Luiz Pereira Campos
}

Resumo

\begin{abstract}
Este trabalho destina-se ao estudo da poesia de Machado de Assis, tomando como ponto de partida seu percurso pelo gênero poético. Os poemas de Gazeta de Holanda satirizam a sociedade brasileira do século XIX. O estudo aqui desenvolvido revela elementos significativos para a compreensão da poética machadiana no plano estético.
\end{abstract}

Palavras-chave: Machado de Assis. Poesia. Sátira. Século XIX. Gazeta de Holanda.

Machado de Assis (1839-1908) encontrou na poesia a sua primeira manifestação literária. Aos quinze anos, publicou seu primeiro soneto em um periódico sem grande importância no Rio de Janeiro do Segundo Império. Tratava-se do Periódico dos pobres, que imprimia, naquela ocasião, o primeiro trabalho literário daquele que viria a ser o escritor mais representativo da literatura brasileira. O jovem poeta, apesar de um início titubeante e canhestro, continuou a compor seus versos, aperfeiçoando-se cada vez mais no trato com a poesia. Dez anos mais tarde, Machado publica seu primeiro livro de poesias Crisálidas (1864), seguido de Falenas (1870), Americanas (1875) e Ocidentais (1901). O último, na verdade, nunca chegou a compor um volume avulso, mas veio a lume na edição das Poesias completas que o próprio autor organizou em 1901.

Interessante é que, passados quase cem anos da morte do escritor, a obra poética machadiana ainda não está completa. Não existe uma edição que reúna toda a poesia de Machado de Assis. Um lapso imperdoável com o grande autor da literatura brasileira. Dessa forma, dois grupos de poemas perdem-se no tempo. Os poemas dispersos, publicados em jornais, álbuns e panfletos, cujo total, seguramente catalogado até agora, soma 86 composições e um outro conjunto de 48 poemas publicados entre 1886 e 1888, na Gazeta de notícias, sob o título Gazeta de Holanda. Este último conjunto será o objeto de análise deste artigo.

Os 48 poemas em quadras, com versos em redondilha maior, reunidos sob o título Gazeta de Holanda, encontram-se nas crônicas por formarem um misto de prosa e poesia, isto é, um gênero híbrido. Essas composições, que ocupavam uma coluna na página do jornal, são verdadeiras crônicas em verso. O principal assunto é - como nas crônicas machadianas - o cotidiano do Rio de Janeiro do século XIX. O tom geral dessas gazetas é a sátira. A verve crítica machadiana apresenta-se com grande liberdade, uma vez que tanto a composição, quanto o jornal em que figurava assim o 
permitia. Os assuntos da semana eram comentados sempre por um viés satírico e bastante crítico. O vocabulário vai da fala popular - que Machado soube captar bem ao registro erudito. É de grande interesse para a poesia machadiana o estudo de tais composições, principalmente porque muitas vezes o autor estabelece uma metapoética capaz de revelar pequenas sutilezas no trato com o verso. Sutilezas típicas de um cultor ininterrupto e eminente estudioso dos versos em língua portuguesa.

Os poemas desse conjunto apresentam a prosa na sua vertente mais aberta ao diálogo com o popular e com o tempo, que é a crônica, e mais popular na forma poética escolhida, a quadra em redondilhas maiores. O tom geral dos poemas é a sátira. Machado critica a sociedade de seu tempo. O pseudônimo escolhido é Malvólio. O cotidiano do Rio de Janeiro do Segundo Império encontra-se exposto em múltiplos detalhes, todos explorados com muito humor: política, nomes de rua, lei sobre animais, jornalismo, abertura de um novo banco, dívidas do tesouro, incêndio na Gamboa, Sociedade Protetora dos Animais, proibição da "capoeiragem", discussão em torno do Poder Moderador, além de composições metalingüísticas e metapoéticas.

Em "Machado de Assis cronista", Gustavo Corção tece considerações que podem ser aplicadas a essas gazetas. Sobre a técnica de composição em particular, afirma o crítico:

Vai de uma coisa aqui para outra acolá, passa do particular para o geral, volta do abstrato ao concreto, desliza do atual para o clássico, galga do pequeno para o grandioso e volta do vultoso para o microscópico, passa do real para o imaginário, e do imaginário para o onírico, às vezes numa progressão geométrica vertiginosa, outras vezes com um cômico aparato lógico, para rir-se da lógica, ou para mostrar que existe efetivamente uma esquisita lógica entre as coisas que o vulgar julga distantes e desconexas. (ASSIS, 1997, p. 327).

Sobre o "humorismo machadiano", fundamental para a compreensão da Gazeta de Holanda, Corção lembra o que dizia Tristão de Ataíde: "a maneira leve de tratar as coisas graves, e a maneira grave de tratar as coisas leves". (ASSIS, 1997, p. 329). Esta assertiva de Ataíde, muito apropriada para as crônicas machadianas em geral, torna-se lapidar em se tratando das "gazetas". Assim como as crônicas, essas gazetas machadianas ligam-se ao tempo e escapam dele. Em outras palavras, tais composições renovam-se e permanecem atuais. Um outro espírito, perspicaz observador de seu tempo, recorreu à sátira no intuito de espelhar a sociedade dos séculos XV e XVI. Trata-se de Erasmo que, na carta-prefácio de Elogio da loucura, dirigida a Thomas Morus, afirma: "Nada é mais tolo do que tratar com seriedade coisas frívolas, nada mais espiritual do que fazer as frivolidades servirem às coisas sérias."(1997, p. 3) Três séculos mais tarde, Machado confirma em seus versos as respectivas assertivas. Veja a apresentação do autor na estréia da Gazeta de Holanda, datada de 1 de novembro de 1886:

Um doutor da mula ruça, Caolho, coxo e maneta, É o homem que se embuça No papel desta gazeta. (p. 281) ${ }^{1}$.

Ainda no mesmo artigo, é a "tinta da galhofa" que apresenta a própria gazeta:

Não traz idéias modernas, Nem antigas: não traz nada. Traz as suas duas pernas, Uma sã, outra quebrada. 
E vem, como é de ciência,

Entre muletas segura,

A muleta da inocência,

E a muleta da loucura. (p. 282).

Eis uma amostra do tom machadiano que perpassa as 48 composições da Gazeta de Holanda. Inocência e loucura. Os dois pontos em que se apóia o gazeteiro. Tal atitude, que evoca naturalmente Erasmo, encontra-se presente em todas as composições desta Gazeta. Note-se o mesmo teor nas duas quadras iniciais da quadragésima segunda gazeta, 28 de dezembro de 1887:

Eu cá, quando toda a gente

Chora ou treme de assustada,

Tenho um desejo veemente

De dar uma gargalhada.

E a razão, - se há razão nisto,

Não é senão porque é útil

Fazer deste mundo um misto

De terrífico e de fútil. (p. 441).

Em decorrência da multiplicidade de assuntos abordados e do volume de composições, torna-se inviável a análise sistemática de toda a Gazeta de Holanda nesse trabalho. Sendo inevitável a seleção, optou-se por dar prioridade às peças que evidenciem o tom satírico do autor e demonstrem a amplitude da crítica dirigida à sociedade carioca do Segundo Império.

No que se refere à estrutura, as peças foram compostas em quadras, o metro escolhido foi a redondilha maior, as rimas aparecem cruzadas (abab) e em alguns casos interpoladas (abba). Todas trazem sempre a mesma epígrafe "Voilà ce que I'on dit de moi/dans la 'Gazette de Hollande'". ${ }^{2}$ Quanto à extensão, existe uma média de 20 quadras por composição, algumas com mais, 25 ou 27, outras com menos, 19, por exemplo. A periodicidade das publicações é quinzenal.

Na segunda gazeta, 5 de novembro de 1886, Machado dialoga com o leitor:

Muito custa uma notícia!

Que ofício! E nada aparece.

Que canseira e que perícia!

Que andar desde que amanhece!

E tu, leitor sem entranhas,

Exiges mais, e não vês

Como perdemos as banhas

Em te dar tudo o que lês. (p. 285).

A oposição entre o jornalista e o leitor provoca o riso. A expressão "leitor sem entranhas" sugere sutilmente a passividade do público leitor.

A terceira gazeta, 12 de novembro de 1886, revela uma crítica mordaz às pessoas que se dizem inteligentes. Tal crítica, entretanto, surge de um anúncio banal e cotidiano a respeito do aluguel de uma beca. Quantos não teriam visto o mesmo anúncio? Reside aí, justamente, o valor do artista Machado de Assis, pois foi capaz de ler, com seus olhos míopes, muito mais que um simples anúncio. Em outras palavras, - cronista desvendou o lado "medalhão"3 de seus contemporâneos. Repare na seqüência de perguntas seguida de um "nada sei", pura retórica machadiana:

Não haverá neste caso

Um sintoma? Não parece 
Que a beca tomada a prazo

Uma lição oferece?

Que, sem correr Seca e Meca, Muita gente delicada, Assim como traz a beca, Traz a ciência alugada?

Que sendo esta leve e pouca, Apenas meia tigela, Não chega a entornar da boca, E pouco pedem por ela?

Que, inda mesmo sendo um quarto

De tal tigela, e não meia,

Parece falar de farto

Quem fala de boca cheia?

E que esse pouco, bastando

A que o locatário almoce,

É tolice andar catando

Ciência de sobreposse?

Nada sei; mas ofereço

A toda a pessoa séria

Este problema de preço;

E passo a outra matéria. (p. 291-292).

A quarta gazeta, 17 de novembro de 1886, discorre sobre a abertura de um novo banco. Machado compara o banco com um "andador de Irmandade", no fundo um esmoleiro. E o faz nestes termos:

É este o meu banco. O fundo

É variável, mas certo;

Deus dá banco a todo o mundo;

Uns vão longe, outros vão perto.

Eu cá não ando com listas

De ações, nem faço rateio;

Todos são meus acionistas,

Gordo ou magro, lindo ou feio. (p. 298).

Machado, com bastante sagacidade, coloca no mesmo patamar o banco e o esmoleiro. Dessa forma, um acontecimento corriqueiro presta-se, na mão do poeta, à crítica social. O banco não passa de um grande esmoleiro que escolhe e seleciona seus acionistas. Em outros termos, Machado nota a avidez da referida instituição pelo dinheiro, personificando-a e, portanto, rebaixando-a à condição de esmoleiro, sempre a espera de gordas esmolas.

Na décima sétima gazeta, o autor critica uma novidade para a época, o uso da hipnose pela medicina. O texto dessa composição apresenta referências metapoéticas, principalmente no que se refere à dificuldade de colocar os nomes em forma de versos. Além disso, e mais apropriado para esse artigo, Machado observa que a "academia", da qual o cronista esperava uma explicação profunda acerca da novidade, simplesmente:

Dá-lhe duas passadelas

De escova, e manda a teoria 
Curar as nossas mazelas. (p. 346).

\section{Continua Malvólio:}

Isto é que me põe os braços

Caídos, e a boca aberta...

E já daqui vejo os passos

Desta nova descoberta.

Atrás dos homens sabidos

Virão os que nada sabem,

E gritarão desabridos

Até que os astros desabem. (p. 347).

A criatividade poética de Machado, principalmente no tocante à forma, torna-se tão original que na décima oitava gazeta ao citar Dante Alighieri o poeta reproduz foneticamente a língua italiana nos dois versos finais de uma quadra. Eis o trecho:

Ah! Goiás... Goiás existe;

E tanto que, a vinte e dois

De março, saiu um triste

E longo bando de grous,

Como os de que fala o Dante,

Que van cantando lor lai;

Mas cá o pio ora ovante,

Era só: quebrai, quebrai! (p. 350-351).

Algumas gazetas abordam a escravidão e a situação dos negros, o que revela um Machado de Assis atento às questões de seu tempo. A vigésima terceira, 20 de agosto de 1887, conta sobre um certo inspetor que, tendo à beira da morte uma escrava, mandou enterrá-la viva:

$E$ que isto de meter gente

Viva em caixão de finado,

Sem exame competente,

Devia ser castigado; (p. 370).

A vigésima nona gazeta, 27 de setembro de 1887, ironiza as discussões em torno da libertação dos escravos. De maneira muito perspicaz, chamando um escravo e perguntando ao próprio sobre sua condição, Machado desvenda a retórica a respeito do assunto, pois, na prática, o escravo continuava escravo. A resposta de "Pai Silvério" é esclarecedora:

- Meu senhor, eu, entra ano,

Sai ano, trabalho nisto;

Há muito senhor humano,

Mas o meu é nunca visto.

Pancada, quando não vendo,

Pancada que dói, que arde;

Se vendo o que ando vendendo,

Pancada, por chegar tarde.

Dia santo nem domingo

Não tenho. Comida pouca:

Pires de feijão, e um pingo

De café, que molha a boca. 
Por isso, digo ao perfeito

Instituto, grande e bravo:

Tu falou muito direito,

Tu tá livre, eu fico escravo. (p. 393).

Na última gazeta, 24 de fevereiro de 1888, Machado, criticando a morosidade do sistema judicial, adverte os criminosos, principalmente os que cometem pequenos furtos. Interessante é que o autor fecha suas gazetas com o tema da inocência, retomando a primeira composição em que a inocência fazia par com a loucura:

Portanto, e vistos os autos,

Dou de conselho prudência,

E digo aos homens incautos

Que inda o melhor é a inocência. (p. 467).

Eis alguns dos temas tratados por Machado de Assis em sua Gazeta de Holanda. A amostra é pequena diante do conjunto das composições, mas, espera-se, significativa para a compreensão dessa outra face, um tanto esquecida, e diga-se de passagem, injustamente esquecida, do Bruxo do Cosme Velho, qual seja: a poesia.

\footnotetext{
Notas

$\prod_{1}$ A edição aqui utilizada é o $4^{\circ}$ volume das Crônicas presente nas Obras completas de Machado de Assis 1961. A indicação das páginas seguirá às citações.

2 Eis o que dizem de mim/ na "Gazeta de Holanda".

${ }^{3} \mathrm{O}$ conto "Teoria do medalhão" presente em Papéis avulsos data de 1882, portanto quatro anos antes dessa gazeta.
}

Abstract

This work aims at analysing Machado de Assis's poetry, having the author's experience while a poet as object of study. The poems of Gazeta de Holanda satirize the Brazilian society of nineteenth century. The study reveals elements which are significant to an aesthetical appreciation of Machado's poetry.

Key words: Machado de Assis. Poetry. Satire. Nineteenth century. Gazeta de Holanda.

Referências

ASSIS, Machado de. Crônicas (1878-1888). São Paulo: W. M. Jackson inc., 1961. v.4.

ASSIS, Machado de. Obra completa. Organizada por Afrânio Coutinho. Rio de Janeiro: Nova Aguilar, 1997.

ROTTERDAM, Erasmo de. São Paulo: Martins Fontes, 1997. 